\title{
The Midlands dental workforce
}

\author{
A dental workforce review for a Midlands Strategic Health Authority \\ P. Hornby, E. Stokes, W. Russell, D. Cochrane and J. Morris Br Dent J 2006; 200: 575-579
}

\section{Objective}

To explore opportunities for workforce development in NHS general dental services (GDS) in Shropshire and Staffordshire.

\section{Method}

Secondary data sources were supplemented with a primary survey of GDS practices to build up a profile of the existing GDS workforce and its current capacity. Attitudes and perceptions on current workforce issues and potential solutions were gathered using a second survey and explored further through other qualitative techniques including interviews and a focus group discussion.

Results

The results confirm that there is a shortage of dentists in the area, fuelled by multiple factors including the move from NHS to private work, the decision to retire early and a growing disillusionment with NHS policies and remuneration. Modelling of alternate approaches to future dental clinical needs highlighted the opportunity for meeting the consequent workforce demands through increased involvement of hygienists and therapists.

\section{Conclusions}

This study has provided local evidence to inform dental service development in Shropshire and Staffordshire. It has provided a starting point for exploring new ways of working and will contribute towards a more effective implementation of new and evolving service strategies.

\section{IN BRIEF}

- The findings from this paper may be used for comparative purposes with other studies and against the national picture.

- The findings complement the national review.

- This study provides a valuable evidence base in response to a range of key issues in order to inform local workforce development.

- The outcomes contribute to both local and wider strategies for ways forward in developing the dental workforce.

\section{COMMENT}

Access to NHS dentistry has continued to be of interest to the Government since the Prime Minister's statement made in September 1999. Increase in the dental workforce has been underwritten by additional national money for an extra 170 dental undergraduate places, and support for domestic and International Recruitment. A written Ministerial Statement on 7 July 2005 confirmed the implementation date of 1 April 2006 for the dental reforms heralded in NHS dentistry: Options for change. ${ }^{1}$ Primary Care Trusts (PCTs) now have the responsibility to develop NHS dental services responsive to local need. Fundamental to the ability of PCTs to commission those services is an understanding of their local dental workforce, including the whole dental team, and its potential to provide more capacity for care.

This project was conducted in a part of the West Midlands with significant problems in access to NHS dental care. It used both quantitative and qualitative approaches to explore existing and future dental workforce requirements relative to needs, and the potential to develop a future workforce congruent with the major changes in policies for NHS dentistry on the immediate horizon. Quantitatively General Dental Council and PCT databases were supplemented by a questionnaire to general dental service (GDS) practices, enabling profiling of the existing NHS workforce. Qualitatively, surveys of GDS dentists were supplemented by semistructured interviews with a sample of individuals from across the whole dental team, plus a focus group discussion with PCT representatives. The quantitative survey responses (70\%) and participation in the interviews and the focus group were high. However only $38 \%$ of dentists replied to the qualitative survey.

The results reported significant turnover in several staff groups, and dentist vacancy factors of $38 \%, 30 \%$ and $26 \%$ in the three geographical areas. All participant groups demonstrated a perception of a substantial shortage of dentists. Concerns were expressed about the age of the workforce, with $30 \%$ of dentists aged 50 or over. Twenty-one per cent of dentists worked in single handed practices. Modelling provided estimates of the minimum number of dentists required, with the additional workload being met by dental therapists and hygienists.

This paper outlines a methodology to establish a dental workforce profile, both quantitatively and qualitatively, to model future requirements; this process could be applied by commissioning organisations to help develop the detailed implementation of the responsibilities for the commissioning of dental services post April 2006.

\section{S. Gregory, Consultant in Dental Public Health, Bedfordshire Heartlands PCT}

1. Department of Health. NHS dentistry: Options for change. London: Department of Health, 2002

doi: 10.1038/sj.bdj.4813589 